\title{
Anthropometric Measures and Body Composition of Soccer Players of Montenegro and Kosovo
}

\author{
Dusko Bjelica ${ }^{1}$, Jovan Gardasevic ${ }^{1}$, Ivan Vasiljevic ${ }^{1}$, Fitim Arifi ${ }^{2}$, Sami Sermaxhaj ${ }^{3}$ \\ 'University of Montenegro, Faculty for Sport and Physical Education, Niksic, Montenegro, ${ }^{2} \mathrm{AAB}$ College, Faculty of Physical Education and Sport, \\ Prishtina, Kosovo, ${ }^{3}$ Universe College, Department of Physical Culture, Sport and Recreation, Prishtina, Kosovo
}

\begin{abstract}
The aim of this research was to determine the differences among the top soccer players of the Montenegrin club FC Mladost and Kosovian club FC Prishtina, in the anthropometric measures and body composition. A sample of 37 examinees is divided into two sub-samples. The first sub-sample of the examinees consisted of 17 players of FC Mladost of the average age of $24.59 \pm 4.66$, the vice champions of the Montenegrin Championship in the season 2016/17, while the other sub-sample consisted of 20 players of FC Prishtina of the average age of $24.30 \pm 4.99$, the vice champions of the Kosovo Championship in the season 2016/17. Soccer players were tested immediately after the end of the competition season 2016/17. Anthropometric measures in the body composition were evaluated by a battery of 10 variables: body height, body weight, waist size, triceps skin set, biceps skin set, back skin set, abdominal skin set, body mass index, fat percentage and muscle mass. The standard central and dispersive parameters of all variables are calculated. The significance of the differences between the players of the top two soccer clubs in the anthropometric measures and variables for assessing body composition was determined by a t-test for independent samples. It was found that the soccer players of the two mentioned clubs have statistically significant differences by the two variables that estimate the body height in a favor of FC Mladost and abdominal skin set in a favor of FC Pristina.
\end{abstract}

Key words: Soccer Players, Anthropometric Measures, Body Composition, Montenegro, Kosovo

\section{Uvod}

Fudbal je najvažnija sporedna stvar na svijetu, sa ogromnim brojem gledalaca na samim stadionima i ispred TV ekrana (Gardašević, 2010; Gardašević, Bjelica, Popović, \& Milašinović, 2016; Gardasevic \& Bjelica, 2019). To je kolektivna igra koju krasi velika brzina i dinamičnost, koja bogatstvom pokreta spada u red polistrukturalnih sportskih igara (Bjelica, 2005; Gardašević i Goranović, 2011; Gardašević i Bjelica, 2013; Gardaševic \& Bjelica, 2014a; Gardasevic i Bjelica, 2014b). Fudbal karakterišu mnogobrojne i raznovrsne složene dinamičke aktivnosti sa velikim brojem cikličnih (Gardašević, Vasiljević, i Bojanić, 2015; Bjelica, Popović, \& Gardašević, 2016a; Bjelica, Popović, i Gardašević, 2016b; Sermaxhaj, Popovic, Bjelica,
Gardasevic, \& Arifi, 2017; Gardasevic, Bjelica, \& Vasiljevic, 2017a; Gardasevic, Bjelica, \& Vasiljevic, 2017b) i acikličnih kretanja (Gardasevic, 2015; Gardašević i sar., 2015; Gardašević, Bjelica, i Vasiljević, 2016a; Gardašević, Bjelica, i Vasiljević, 2016b; Gardasevic, Bjelica, Milasinovic, i Vasiljevic, 2016; Gardaševic i Vasiljević, 2016; Gardasevic, Popovic, \& Bjelica, 2016). Da bi se postigli vrhunski rezultati u fudbalu, igrači moraju proći dugogodišnji programirani trenažni proces (Gardašević, Bjelica, i Popović, 2015; Gardasevic \& Bjelica, 2018). A da bi se kvalitetno upravljalo procesom sportskog treninga moraju se dobro poznavati strukture pojedinih antropoloških sposobnosti igrača, kao i njihov razvoj (Bjelica i Popović, 2012; Bjelica, 2013). Raznim istraživanjima su utvrđeni određeni

\section{Correspondence:}

\section{Montenegro}

Spart

\section{J. Gardasevic}

University of Montenegro, Faculty for Sport and Physical Education, Narodne omladine bb, 81400, Niksic, Montenegro

E-mail: jovan@ucg.ac.me 
principi i zakonitosti transformacionih procesa antropoloških karakteristika bitnih za fudbal (Gardašević, Bjelica, Georgiev, \& Popović, 2012; Gardasevic, Bjelica, \& Corluka, 2018) a među njima naravno i morfoloških karakteristika. Morfološke karakteristike igrača su jako važne u fudbalu (Gardasevic, Bjelica, \& Vasiljevic, 2019). Poznato je da morfološki prostor definišu longitudinalna dimenzionalnost skeleta, transverzalna dimenzionalnost skeleta, masa i volumen tijela (Bjelica \& Fratrić, 2011). Svrha morfoloških karakteristika je da poboljšaju vještine kod sportista u mnogim sportovima. Uglavnom je kod vrhunskih sportista, u zavisnosti od sporta kojim se bave morfološki status relativno homogen. Istraživanja morfoloških karakteristika među sportistima različitih sportova ukazuju na to da sportisti različitih sportova imaju svoja specifična obilježja. Mišićna masa poboljšava sportsko postignuće u aktivnostima koje zahtijevaju mišićnu snagu i izdržljivost, ali i u onima koje zahtijevaju zavidnu aerobnu sposobnost (Ramadan \& Byrd, 1987; Green, 1992; Rico-Sanz, 1998). Pripadnost sportiste jednoj sportskoj grani podrazumijeva njegov biotip, koji mu daje prednost da se bavi baš tim sportom u odnosu na druge.

Ono što se sa sigurnošću može tvrditi da je fudbal danas po gledanosti, popularnosti, količini novca koji se vrti, medijskoj pažnji, sigurno sport broj jedan u svijetu (Gardašević, Georgiev, \& Bjelica, 2012; Vasiljević, Gardašević, \& Bojanić, 2013). Definitivno da drugačije nije ni u zemljama kao što je Crna Gora i u regionu koji je okružuje. Jedan od većih fudbalskih klubova u Crnoj Gori, koji se svake godine bori za trofeje je FK Mladost iz Podgorice, koji je u sezoni 2018/19 promijenio ime u OFK Titograd, ali u momentu kada su utvrđivane mjere koje su predmet ovog istraživanja imao je naziv FK Mladost pa će i u ovom radu biti korišćeno to ime kluba. Još jedan klub iz regiona, koji je bio veoma poznat i u ligi nekadašnje Jugoslavije i koji ima značajnu tradiciju je FK Pristina iz Kosova. Nastavili su sa dobrim rezultatima i u tamošnjoj ligi i takođe se svake godine bore za jedan od trofeja na Kosovu. Oni su u odigranoj takmičarskoj sezoni 2016/17., svaki u domaćem takmičenju u svojim državama zauzeli drugo mjesto na tabeli i dobili pravo igranja u međunarodnim takmičenjima pod okriljem UEFA-e u sklopu kvalifikacija za Ligu Evrope. Fudbal u regionu je vrlo sličnog kvaliteta (Gardasevic, Bjelica, Vasiljevic, Arifi, \& Sermaxhaj, 2019), budžeti klubova su vrlo slični, pa samim tim se očekuje i da utvrđivane varijable koje su predmet ovog istraživanja kod fudbalera ova dva kluba budu na sličnom nivou. Dodatnu težinu ovom istraživanju daje činjenica da su oba kluba stekla pravo igranja na međunarodnoj sceni.

Cilj istraživanja je bio da se utvrde morfološke karakteristike i sastav tijela kod vrhunskih fudbalera ova dva kluba i njihove eventualne razlike.

\section{Metod}

Podaci dobijeni u istraživanju morfoloških karakteristika i sastava tijela, kontrolisani su i pripremljeni za obradu u skladu sa postavljenim ciljem. Baze podataka su sređene po praćenim obilježjima i pripremljene za planiranu statističku obradu. Rezultati dobijeni statističkom obradom prikazani su u tabelama i analizirani po pripadajućim logičkim cjelinama. U cjelini posmatrano, prikaz rezultata istraživanja, kroz postupnost u obrazlaganju pojedinačnih veza, omogućava sagledavanje razlika u posmatranim morfološkim mjerama i sastavu tijela, u skladu sa ciljem istraživanja, odnosno doprinosi jasnom određenju prema očekivanoj primjeni dobijenih rezultata u praksi. U pogledu vremenske određenosti istraživanje je transverzalnog karaktera, a sastoji se u jednokratnom mjerenju odgovarajućih morfoloških karakteristika i sastava tijela vrhunskih fudbalera seniora.

\section{Uzorak ispitanika}

Ukupan uzorak ispitanika je brojao 37 vrhunskih fudbalera, koji su članovi dva kluba koji nastupaju u Prvoj fudbalskoj ligi Crne Gore (FK Mladost) i u Superligi Kosova (FK Pristina). Prvi subuzorak su činili 17 igrača FK Mladost prosječne starosti $24.59 \pm 4.66$ godina, koji su u sezoni 2016/17. bili vicešampioni (drugo mjesto) Crne Gore, a drugi subuzorak se sastojao od 20 igrača FK Pristina prosječne starosti $24.30 \pm 4.99$ godina, koji su takođe bili vicešampioni u ligi Kosova u sezoni $2016 / 17$. Fudbaleri su testirani neposredno nakon okončanja takmičarske sezone 2016/17.

\section{Uzorak mjera}

Antropometrijsko istraživanje sprovedeno je uz poštovanje osnovnih pravila i principa vezanih za izbor mjernih instrumenata i tehnike mjerenja koji su standardizovani prema upustvima Internacionalnog Biološkog Programa. Za potrebe ovog istraživanja izmjereno je 7 antropometrijskih mjera: visina tijela (ATV), težina tijela (ATM), obim struka (AOS), kožni nabor tricepsa (ANT), kožni nabor bicepsa (ANB), kožni nabor leđa (ANL), kožni nabor trbuha (ANS), i 3 varijable za procjenu sastava tijela: indeks tjelesne mase (BMI), procenat masti (APM) i mišićna masa (AMM). Za antropometrijsko mjerenje korišćeni su antropometar, kaliper i centimetarska traka. Za procjenu sastava tijela korišćena je tanita vaga, model BC-418MA. Princip rada ove vage je zasnovan na indirektnom mjerenju tjelesnog sastava, tako što se bezbjedan električni signal šalje kroz tijelo preko elektroda smještenih u samostalnoj jedinici. Tanita vaga, zahvaljujući atletskom modu koje posjeduje, omogućava sportistima detaljno praćenje tjelesne težine, zdrastvenog stanja i kondicije, sa svim relevantnim parametrima.

\section{Metode obrade podataka}

Podaci dobijeni istraživanjem obrađeni su postupcima deskriptivne i komparativne statističke procedure. Za svaku varijablu su obrađeni centralni i disperzioni parametri kao i mjere asimetrije i spljoštenosti. Razlike u morfološkim karateristikama i sastavu tijela fudbalera ova dva Kluba utvrđene su primjenom diskriminativne parametrijske procedure, Studentovim t-testom za male nezavisne uzorke, sa statističkom značajnošću od $\mathrm{p}<0.05$.

\section{Rezultati}

U Tabelama 1 i 2 prikazani su osnovni deskriptivni statistički parametri antropometrijskih varijabli i sastava tijela fudbalera dva kluba, gdje su izračunate vrijednosti mjera centralne i disperzione tendencije i to: aritmetička sredina (Mean), standardna devijacija (Std. Dev.), varijansa (Variance), minimalne (Min) i maksimalne (Max) vrijednosti, koeficijenti zakrivljenosti (Skewness) i izduženosti (Kurtosis). Prvo su analizirani centralni i disperzioni parametri varijabli za procjenu morfoloških karakteristika i sastava tijela igrača FK Mladost (Tabela 1.). 
Tabela 1. Centralni i disperzioni parametri varijabli za procjenu morfoloških karakteristika i sastava tijela igrača FK Mladost $(\mathrm{N}=17)$

\begin{tabular}{lccccccccc}
\hline \multirow{2}{*}{ Variable } & Min & Max & Mean & S.D. & Variance & \multicolumn{2}{c}{ Skewness } & \multicolumn{2}{c}{ Kurtosis } \\
& & & & & & Stat. & S.E. & Stat. & S.E. \\
\hline ATV & 175.3 & 195.3 & 183.476 & 6.0257 & 36.309 & .350 & .550 & -1.067 & 1.063 \\
ATM & 71.3 & 92.8 & 79.376 & 5.9193 & 35.038 & .648 & .550 & .290 & 1.063 \\
AOS & 79.0 & 93.0 & 84.59 & 3.809 & 14.507 & .514 & .550 & .117 & 1.063 \\
ANT & 3.7 & 11.6 & 6.806 & 2.2064 & 4.868 & .699 & .550 & -.180 & 1.063 \\
ANB & 3.5 & 7.0 & 4.718 & 1.2320 & 1.518 & .764 & .550 & -.896 & 1.063 \\
ANL & 6.0 & 14.0 & 9.16 & 1.782 & 3.174 & .872 & .550 & 1.379 & 1.063 \\
ANS & 5.6 & 17.2 & 9.718 & 3.5534 & 12.627 & 1.103 & .550 & .223 & 1.063 \\
BMI & 21.2 & 25.3 & 23.524 & 1.0299 & 1.061 & -.347 & .550 & .249 & 1.063 \\
APM & 7.9 & 16.1 & 11.876 & 2.3771 & 5.651 & -.048 & .550 & -.724 & 1.063 \\
AMM & 34.8 & 46.4 & 39.600 & 3.1016 & 9.620 & .783 & .550 & .752 & 1.063 \\
\hline
\end{tabular}

Legenda: Min - Minimalna vrijednost; Max - Maksimalna vrijednost; Mean - Aritmetička sredina; S.D. - Standardna devijacija; Variance - Varijansa; Skewness - Mjera asimetrije; Kurtosis - Mjera spljoštenosti; Stat. - Statistička vrijednost; S.E. - Standardna greška

Na osnovu centralnih i disperzionih parametara, vrijednosti skjunisa i kurtozisa igrača FK Mladost, može se konstatovati da su sve varijable u granicama normalne raspodjele. Po vrijednosti skjunisa vidi se da je kod varijable nabor trbuha (ANS) došlo do male nagnutosti u stranu manjih rezultata što je dobro jer je potkožno masno tkivo remeteći faktor za profesionalne sportiste. Vrijednosti kurtozisa kod varijabli nabor leđa (ANL) i koštana masa (AKM) obrazuju blagu leptokurtičnu krivu što govori o priličnoj ujednačenosti igračkog kadra FK Mladost u ovim dvijema varijablama. Varijabla tjelesna visina (ATV) obrazuje blagu platikurtičnost krive, što znači blagu raspršenost rezultata u visini, što je i normalno obzirom da po linijama tima igrači (golmani, odbrana, vezni red i napadači) imaju različitu konstituciju i potrebnu tjelesnu visinu. Kod golmana, centralnih odbrambenih igrača i centralnih napadača uglavnom je dominantna visina, dok kod veznih i bočnih igrača nije toliko bitna i presudna.

Tabela 2. prikazuje centralne i disperzione parametre varijabli za procjenu morfoloških karakteristika i sastava tijela igrača FK Pristina.

Tabela 2. Centralni i disperzioni parametri varijabli za procjenu morfoloških karakteristika i sastava tijela igrača FK Pristina $(\mathrm{N}=20)$

\begin{tabular}{lccccccccc}
\hline \multirow{2}{*}{ Variable } & \multirow{2}{*}{ Min } & \multirow{2}{*}{ Max } & Mean & S.D. & Variance & \multicolumn{2}{c}{ Skewness } & \multicolumn{2}{c}{ Kurtosis } \\
& & & & & & Stat. & S.E. & Stat. & S.E. \\
\hline ATV & 168.0 & 188.5 & 179.725 & 5.1898 & 26.934 & -.406 & .512 & -.177 & .992 \\
ATM & 63.9 & 90.1 & 75.430 & 7.8136 & 61.053 & .342 & .512 & -.609 & .992 \\
AOS & 75.0 & 95.0 & 83.600 & 4.6043 & 21.200 & .246 & .512 & 1.251 & .992 \\
ANT & 3.4 & 11.0 & 6.255 & 2.1659 & 4.691 & .898 & .512 & .019 & .992 \\
ANB & 2.8 & 8.4 & 4.460 & 1.4332 & 2.054 & 1.655 & .512 & 2.619 & .992 \\
ANL & 6.4 & 14.8 & 8.890 & 2.0264 & 4.106 & 1.382 & .512 & 2.762 & .992 \\
ANS & 4.8 & 13.2 & 7.795 & 1.8878 & 3.564 & .979 & .512 & 2.310 & .992 \\
BMI & 19.6 & 26.6 & 23.315 & 1.6493 & 2.720 & -.464 & .512 & .568 & .992 \\
APM & 2.0 & 16.4 & 10.405 & 3.8282 & 14.655 & -.558 & .512 & -.186 & .992 \\
AMM & 32.6 & 44.8 & 38.180 & 3.4567 & 11.949 & .213 & .512 & -.939 & .992 \\
\hline
\end{tabular}

$\mathrm{Na}$ osnovu centralnih i disperzionih parametara, vrijednosti skjunisa i kurtozisa igrača FK Pristina, može se konstatovati da su sve varijable u granicama normalne raspodjele i da su vrijednosti vrlo slične fudbalerima FK Mladost. Takođe se može konstatovati da su igrači FK Pristina u prosjeku niži i lakše tjelesne težine od igrača FK Mladost, kao i da imaju niže vrijednosti svih kožnih nabora, istina neznatno, međutim da li i statistički značajno, pokazaće komparativna statistička procedura, t-test (Tabela 3.). Po vrijednosti skjunisa vidi se da je kod varijabli nabor bicepsa (ANB) i nabor leđa (ANL) došlo do male nagnutosti u stranu manjih rezultata što je dobro jer je potkožno masno tkivo remeteći faktor za profesionalne fudbalere. Vrijednosti kurtozisa kod varijable obim struka (AOS) obrazuje blagu leptokurtičnu krivu što govori o priličnoj ujednačenosti igračkog kadra FK Pristina u ovoj varijabli, a kod tri varijable nabor bicepsa (ANB), nabor leđa
(ANL) i nabor trbuha (ANS) obrazuje leptokurtične krive i pokazuje statistički značajnu izoštrenost što govori da je veliki broj rezultata u ovim varijablama raspoređen oko aritmetičke sredine.

Da bi se utvrdilo da li ima statistički značajne razlike u analiziranim varijablama kod vrhunskih fudbalera ova dva kluba, FK Mladost iz Crne Gore i FK Pristina sa Kosova, primjenjena je statistička procedura t-test za male nezavisne uzorke (Tabela 3.).

$\mathrm{Na}$ osnovu dobijenih vrijednosti rezultata t-testa, može se primijetiti da postoji statistički značajna razlika u dvije varijable na nivou značajnosti $\mathrm{p}<0.05$, a to je tjelesna visina u korist fudbalera FK Mladost i kožni nabor stomaka, u korist fudbalera članova FK Pristina. Može se primijetiti da fudbaleri FK Pristina imaju neznatno bolje rezultate i u ostalim varijablama koje procjenjuju potkožno masno tkivo i procenat masti od fudbalera FK Mladost, međutim ne i statistički značajno. 
Tabela 3. Vrijednosti t-testa između aritmetičkih sredina varijabli za procjenu morfoloških karakteristika i sastava tijela igrača FK Mladost $(\mathrm{N}=17)$ i FK Pristina $(\mathrm{N}=20)$

\begin{tabular}{lccccccc}
\hline & Club & Mean & S.D. & S.E. & F & Sig. & M.D. \\
\hline \multirow{2}{*}{ ATV } & MLA & 183.476 & 6.0257 & 1.4615 & & & \\
& PRI & 179.725 & 5.1898 & 1.1605 & 2.035 & .049 & 3.7515 \\
ATM & MLA & 79.376 & 5.9193 & 1.4356 & & & \\
& PRI & 75.430 & 7.8136 & 1.7472 & 1.706 & .097 & 3.9465 \\
AOS & MLA & 84.588 & 3.8089 & .9238 & & & \\
& PRI & 83.600 & 4.6043 & 1.0296 & .703 & .486 & .9882 \\
ANT & MLA & 6.806 & 2.2064 & .5351 & & & \\
& PRI & 6.255 & 2.1659 & .4843 & .764 & .450 & .5509 \\
ANB & MLA & 4.718 & 1.2320 & .2988 & & & \\
& PRI & 4.460 & 1.4332 & .3205 & .581 & .565 & .2576 \\
ANL & MLA & 9.159 & 1.7815 & .4321 & & & \\
& PRI & 8.890 & 2.0264 & .4531 & .425 & .674 & .2688 \\
ANS & MLA & 9.718 & 3.5534 & .8618 & & & \\
& PRI & 7.795 & 1.8878 & .4221 & 2.099 & .043 & 1.9226 \\
BMI & MLA & 23.524 & 1.0299 & .2498 & & & \\
& PRI & 23.315 & 1.6493 & .3688 & .451 & .655 & .2085 \\
APM & MLA & 11.876 & 2.3771 & .5765 & & & \\
& PRI & 10.405 & 3.8282 & .8560 & 1.374 & .178 & 1.4715 \\
AMM & MLA & 39.600 & 3.1016 & .7523 & & & \\
& PRI & 38.180 & 3.4567 & .7730 & 1.305 & .200 & 1.4200 \\
\hline
\end{tabular}

Legenda: MLA - FK Mladost; PRI - FK Pristina; Club - klub; Mean - Aritmetička sredina; S.D. - Standardna devijacija; S.E. - Standardna greška; F - Vrijednost T testa; Sig. - Značajnost razlike; M.D. - Srednja razlika

\section{Diskusija}

Cilj ovog istraživanja je bio da se utvrdi nivo antropometrijskih karakteristika i sastav tijela vrhunskih igrača dva fudbalska kluba, FK Mladost iz Crne Gore i FK Pristina iz Kosova, kao i njihove eventualne razlike. Ovo je nastavak niza istraživanja koje je ovaj istraživački tim napravio u regionu kada se javila ideja da se upoređuju fudbaleri iz susjednih država koji su nekada igrali u zajedničkoj ligi, kakav je sada njihov odnos i eventualna razlika u pomenutim istraživanim varijablama. Uzorak od ukupno 37 ispitanika je podijeljen na dva subuzorka. Prvi subuzorak ispitanika su činili 17 igrača FK Mladost prosječne starosti $24.59 \pm 4.66$ godina, koji su u sezoni 2016/17. zauzeli drugo mjesto na prvenstvenoj tabeli, a drugi subuzorak se sastojao od 20 igrača FK Pristina prosječne starosti $24.30 \pm 4.99$ godina, koji su takođe zauzeli drugo mjesto u ligi Kosova u sezoni 2016/17. Kao što se vidi igrači oba kluba su bili skoro iste prosječne starosti. Rezultati u prostoru antropometrijskih karakteristika i sastava tijela su dali osnov za diskusiju. Uvidom u osnovne deskriptivne statističke parametre se može zaključiti da se radi o profesionalnim sportistima i da su njihovi rezultati vrlo slični rezultatima fudbala koji igraju u istim ligama (Corluka \& Vasiljevic, 2018; Gardasevic, Bjelica, Popovic, Vasiljevic, \& Milosevic, 2018; Bjelica, Gardasevic, \& Vasiljevic, 2018) ili u regionu (Gardasevic, Bjelica, Vasiljevic, Sermaxhaj, \& Arifi, 2018; Corluka et al., 2018; Bjelica, Gardasevic, Vasiljevic, \& Corluka, 2018). Vidi se da su igrači oba kluba približnih srednjih vrijednosti analiziranih varijabli, što i ne čudi jer se radi o jednom klubu koji ima dugu tradiciju i dobre rezultate u Crnoj Gori i jednom klubu iz Kosova koji je po tim parametrima sigurno najveći u svojoj državi. Oni su u sezoni iz koje su izašli ostvarili značajne rezultate, pa se moglo očekivati da je $u$ ta dva kluba značajna koncentracija boljih igrača u ovim dvijema državama. Rezultati i ovog istraživanja su potvrdili hipotezu da je kvalitet igrača fudbala vrlo sličan u regionu. Prosječna tjelesna visina igrača FK Mladost odgovara i rezultatima istraživanja (Bjelica et al, 2012; Popovic, Bjelica, Tanase, \& Milasinovic, 2015), koji su pokazali da su Crnogorci među najvišim narodima u Evropi.

Rezultati t-testa su pokazali postojanje statistički značajne razlike samo u dvije od svih analiziranih varijabli, u tjelesnoj visini i kožnom naboru stomaka. Što se tiče tjelesne visine, ona u modernom fudbalu nije presudna, jer je opšte poznato da, danas dvije ponajbolje ekipe na svijetu po rezultatima FK Barselona i FK Mancester siti, se ne mogu pohvaliti prosječnom visinom svojih fudbalera. Postoje ekipe koje tu prednost koriste u skoku i tjelesna visina iz tog razloga može biti veoma dobro oružje kod pojedinih ekipa.

Uvidom u tabele, evidentno je da igrači FK Pristina imaju manje vrijednosti potkožnih nabora kao i procenat masti od fudbalera FK Mladost, međutim te razlike, osim nabora stomaka, nijesu statistički značajne, pa se može zaključiti da su procenti masti kod svih fudbalera u okvirima normativnih vrijednosti procenata masti koje iznose od 6-13\%. Treneri obje ekipe mogu biti zadovoljni sa stanjem svojih igrača u pomenutim varijablama, međutim, sigurno da i tu može doći do određenog poboljšanja. Ovo je samo jedan od segmenata koje treba analizirati kod igrača, a vrlo značajno bi bilo provjeriti i funkcionalno-motorički status pomenutih igrača, zatim njihov psihološki profil, kao i nivo taktičke obučenosti, što bi dalo korisnu ukupnu sliku njihovim stručnim štabovima, koji bi kroz sveobuhvatnu analizu došli do zaključka šta bi se moglo poboljšati u radu sa igračima i dovesti do boljih rezultata. Rezultati koji su dobijeni ovim istraživanjem mogu poslužiti kao modelni parametri u procjenjivanim varijablama za ostale igrače, članove fudbalskih klubova u Crnoj Gori i na Kosovu, jer analizirani fudbaleri igraju za dva kluba koji su napravili u toj takmičarskoj godini značajne rezultate u svojim državama, a samim tim su među najboljim i najuspješnijim u njima. 
Acknowledgements

There are no acknowledgements.

\section{Conflict of Interest}

The authors declare that there are no conflicts of interest.

Received: 5 February 2019| Accepted: 25 March 2019| Published: 19 April 2019

\section{References}

Bjelica, D. (2005). Sistematizacija sportskih disciplina i sportski trening. Podgorica: Crnogorska sportska akademija.

Bjelica, D. (2013). Teorija sportskog treninga. Podgorica: Univerzitet Crne Gore.

Bjelica, D., \& Fratrić, F. (2011). Sportski trening: teorija, metodika i dijagnostika. Nikšić: Fakultet za sport i fizičko vaspitanje.

Bjelica, D., i Popović, S. (2012). Fudbal-teorija, tehnika i taktika. Podgorica: Crnogorska sportska akademija.

Bjelica, D., Popovic, S., Kezunovic, M., Petkovic, J., Jurak, G., \& Grasgruber P. (2012). Body Height and Its Estimation Utilizing Arm Span Measurements in Montenegrin Adults. Anthropological Notebooks, 18(2):69-83.

Bjelica, D., Popović, S., i Gardašević, J. (2016a). Modeli fizičke pripreme vrhunskih sportaša i doziranje opterećenja. U Zborniku radova 14. godišnje međunarodne konferencije "Kondicijska priprema sportaša" (185189), Zagreb: Udruga kondicijskih trenera Hrvatske.

Bjelica, D., Popović, S., i Gardašević, J. (2016b). Opći principi planiranja i programiranja fizičkih priprema sportaša. U Zborniku radova 14. godišnje međunarodne konferencije "Kondicijska priprema sportaša" (190-192). Zagreb: Udruga kondicijskih trenera Hrvatske.

Bjelica, D., Gardasevic, J., \& Vasiljevic, I. (2018). Differences in the morphological characteristics and body composition of soccer players FC Sutjeska and FC Mladost in Montenegro. Journal of Anthropology of Sport and Physical Education, 2(2), 31-35. doi: 10.26773/jaspe.180406

Bjelica, D., Gardasevic, J., Vasiljevic, I., \& Corluka, M. (2018). Body composition and anthropometric measures of soccerers, cup winners of Montenegro and Bosnia and Herzegovina. Journal of Anthropology of Sport and Physical Education, 2(4), 3-7. doi: 10.26773/jaspe.181001

Corluka, M., Bjelica, D., Vasiljevic, I., Bubanja, M., Georgiev, G., \& Zeljko, I. (2018). Differences in the morphological characteristics and body composition of soccer players of HSC Zrinjski Mostar and FC Siroki Brijeg in Bosnia and Herzegovina. Sport Mont, 16(2), 77-81. doi: 10.26773/ smj.180614

Corluka, M., \& Vasiljevic, I. (2018). Differences in the morphological characteristics and body composition of soccer players in Montenegro. Journa of Anthropology of Sport and Physical Education, 2(1), 3-7. doi: 10.26773/ jaspe.180101

Gardašević, J. (2010). Efekti programiranog rada u pripremnom periodu na transformaciju bazično-motoričkih i situaciono-motoričkih sposobnost kod fudbalera kadetskog uzrasta. Neobjavljena magistarska teza, Nikšić Fakultet za sport i fizičko vaspitanje.

Gardašević, J., i Goranović, K. (2011). Efekti programiranog rada u pripremnom periodu na transformaciju eksplozivne snage kod fudbalera kadeta. Sport Mont, 9(28-30), 55-62.

Gardašević, J., Georgiev, G., \& Bjelica, D. (2012). Qualitative changes of basic motor abilities after completing a six-week training programme. Acta Kinesiologica, 6(1), 70-74.

Gardašević, J., Bjelica, D., Georgiev, G., \& Popović, S. (2012). Transformation of situational motor abilities with soccer players-cadets. In Proceeding book, XVI International Scientific Congress "Olympic Sports and Sport for All" \& VI International Scientific Congress "Sport, Stress, Adaptation" (373377). Sofia: National Sports Academy "Vassil Levski".

Gardašević, J., i Bjelica, D. (2013). Efekti programiranog trenažnog rada u trajanju od šest nedjelja na transformaciju fleksibilnosti kod fudbalera kadetskog uzrasta. Sport Mont, 11(37-39), 212-217.

Gardaševic, J., \& Bjelica, D. (2014a). The effects of the training in the preparation period on the dribbling speed with fifteen years old soccer players. In Book of Abstracts of the 11th International Scientific Conference on Transformation Process in Sport "Sport Performance" (22-23). Podgorica: Montenegrin Sports Academy.

Gardasevic, J., i Bjelica, D. (2014b). Efekti rada u pripremnom periodu na brzinu vođenja lopte petnaestogodišnjih fudbalera. Sport Mont, 12(40-42), 160-166.

Gardašević, J., Vasiljević, I., \& Bojanić, D. (2015). Six-week preparation period and its effects on coordination transformation with soccer players under 16. In Book of Abstracts 11th International Scientific Conference Management, Sport, Olympism (36). Beograd: Fakultet za menadžment u sportu, Alfa univerzitet.

Gardasevic, J. (2015). The effects of the training in the preparation period on the agility transformation with cadet level soccer players. In Book of
Abstracts of the 12th International Scientific Conference on Transformation Process in Sport "Sport Performance" (76-77). Podgorica: Montenegrin Sports Academy.

Gardašević, J., Vasiljević, I., Bojanić, D., Muratović, A., Ljubojević, M., Milašinović, R., \& Bubanja, M. (2015). Six-week Preparation Period and its Effects on Transformation Movement Speed with Soccer Players Under 16. In Book of Abstracts, International Scientific Conference "Effects of Physical Activity Application to Anthropological Status with Children, Youth and Adults" (148). Belgrade:University of Belgrade: Faculty of Sport and Physical Education.

Gardašević, J., Bjelica, D., i Popović S. (2015). Efekti programiranog rada tokom pripremnog perioda na transformaciju agilnosti kod fudbalera kadetskog uzrasta. Sport Mont, 13(43-45), 355-360.

Gardašević, J., Bjelica, D., \& Vasiljević, I. (2016a). Six-Week Preparation Period and its Effects on Transformation Movement Speed with Soccer Players Under 16. Sport Mont, 14(1), 13-16.

Gardašević, J., Bjelica, D., \& Vasiljević, I. (2016b). The Effects of the Training in the Preparation Period on the Repetitive Strength Transformation With Cadet Level Soccer Players. In Book of Abstracts of the 13th International Scientific Conference on Transformation Processes in Sport "Sport Performance" (43). Podgorica: Montenegrin Sports Academy.

Gardasevic, J., Bjelica, D., Milasinovic, R., \& Vasiljevic, I. (2016). The Effects of the Training in the Preparation Period on the Repetitive Strength Transformation with Cadet Level Soccer Players. Sport Mont, 14(2), 31-33.

Gardaševic, J., \& Vasiljević, I. (2016). Effects of Preparation Period on Endurance in U16 Soccer Players. In Book of Abstracts of the 4TH International Scientific Conference "Exercise and Quality of Life" (108). Novi Sad: University of Novi Sad, Faculty of Sport and Physical Education.

Gardašević, J., Bjelica, D., Popović, S., \& Milašinović, R. (2016). Preparation Period and its Effects on the Speed of Ball Leading at Players U16. In Book of Summaries of 11th FIEP European Congress "Anthropological Aspects of Sport, Physical Education and Recreation" (30-31). Banjaluka: University of Banjaluka, Faculty of Physical Education and Sport.

Gardasevic, J., Popovic, S., \& Bjelica, D. (2016). After preparation period ball shooting accuracy at players U15. In Abstract Book of the 8th Conference for Youth Sport (88), Ljubljana: University of Ljubljana, Faculty of Sport.

Gardasevic, J., Bjelica, D., \& Vasiljevic, I. (2017a). The strength of kicking the ball after preparation period with U15 soccer players. In Book of Abstracts of the 14th International Scientific Conference on Transformation Processes in Sport "Sport Performance" (65-66). Podgorica: Montenegrin Sports Academy.

Gardasevic, J., Bjelica, D., \& Vasiljevic, I. (2017b). The Strength of Kicking the Ball after Preparation Period with U15 Soccer Players. Sport Mont, 15(2), 39-42.

Gardasevic, J., Bjelica, D., \& Corluka, M. (2018). The impact of the preparation period on endurance at soccer players U16. Sport Mont, 16(1), 21-24. doi: 10.26773/smj.180204

Gardasevic, J., Bjelica, D., Popovic, S., Vasiljevic, I., \& Milosevic, Z. (2018). Differences in the morphological characteristics and body composition of soccer players FC Buducnost and FC Mladost in Montenegro. Journal of Anthropology of Sport and Physical Education, 2(1), 51-55. doi: 10.26773/ jaspe.180109

Gardasevic, J., Bjelica, D., Vasiljevic, I., Sermaxhaj, S., \& Arifi, F. (2018). Differences in the morphological characteristics and body composition of soccer players FC Trepca ' 89 and FC Prishtina in Kosovo. Journal of Anthropology of Sport and Physical Education, 2(3), 105-109. doi: 10.26773/ jaspe.180718

Gardasevic, J. \& Bjelica, D. (2018). Preparation period and its impact on the ball control with U16 soccer players. Kinesiologia Slovenica, 24(3), 31-36.

Gardasevic, J., \& Bjelica, D. (2019). Shooting ball accuracy with u16 soccer players after preparation period. Sport Mont, 17(1), 29-32. doi: 10.26773/ smj. 190205

Gardasevic, J., Bjelica, D., Vasiljevic, I., Arifi, F., \& Sermaxhaj, S. (2019). Differences in anthropometric measures of footballers, cup winners of Montenegro and Kosovo. Journal of Anthropology of Sport and Physical Education, 3(1), 23-27. doi: 10.26773/jaspe.190105

Gardasevic, J., Bjelica, D., \& Vasiljevic, I. (2019). Morphological characteristics and body composition of elite soccer players in Montenegro. Int. J. Morphol., 37(1), 284-288.

Green, S. (1992). Anthropometric and physiological characteristics of south Australian soccer players. Australian Journal of Science and Medicine in Sport, 24, 3-7.

Popovic, S., Bjelica, D., Tanase, G.D., \& Milasinovic, R. (2015). Body Height and Its Estimation Utilizing Arm Span Measurements in Bosnian and Herzegovinian Adolescents. Montenegrin Journal of Sports Science and Medicine, 4(1), 29-36

Ramadan, J., \& Byrd, R. (1987). Physical characteristics of elite soccer players. Journal of Sports Medicine and Physical Fitness, 27, 424-428.

Rico-Sanz, J. (1998). Body composition and nutritional assessments in soccer. 
International Journal of Sport Nutrition, 8, 113-123.

Sermaxhaj, S., Popovic, S., Bjelica, D., Gardasevic, J., \& Arifi, F. (2017). Effect of recuperation with static stretching in isokinetic force of young socce players. Journal of Physical Education and Sport, 17(3), 1948-1953. doi: 10.7752/jpes.2017.03191
Vasiljević, I., Gardašević, J., i Bojanić, D. (2013). Uporedna analiza motoričkog prostora između aktivnih fudbalera kadetskog uzrasta i učenika srednje škole. U Zborniku naučnih i stručnih radova VI međunarodni simpozijum "Sport i zdravlje" (212-215), Tuzla: Fakultet za tjelesni odgoj i sport. 